\title{
Çocuk hastalarda alt ekstremite ağrısı etiyolojisine yönelik retrospektif değerlendirme
}

\section{An etiological-based retrospective evaluation of lower extremity pain in pediatric patients}

\author{
Öznur Küçük*, Murat Korkmaz, Yalçın Erdoğan, Suat Biçer
}

Çocuk Sağlığı ve Hastalıkları Anabilim Dalı (Yrd. Doç. Dr. Ö. Küçük, Yrd. Doç. Dr. S. Biçer), Yeditepe Üniversitesi Tıp Fakültesi, TR-34755 İstanbul, Ortopedi ve Travmatoloji Anabilim Dalı (Yrd. Doç. Dr. M. Korkmaz), Aile Hekimliği Anabilim Dalı (Yrd. Doç. Dr. Y. Erdoğan), Bozok Üniversitesi Tıp Fakültesi, TR-66200 Yozgat

\section{Özet}

Amaç. Çocuklarda alt ekstremite ağrısına neden olan etiyolojilerin saptanması ve büyüme ağrılarının etiyolojideki yerinin belirlenmesi amaçlandı. Yöntem. Kasım- Nisan 2011 tarihleri arasında Ortopedi ve Travmatoloji, Çocuk ve Aile Hekimliği polikliniklerine alt ekstremite ağrısı şikayeti ile başvuran 3-15 yaş grubundaki çocuk hastaların demografik ve klinik özellikleri, tanılarına ait bilgiler ve tetkik sonuçları poliklinik dosya kayıtlarından geriye dönük olarak elde edildi. Bulgular. Alt ekstremite ağrısı ile başvuran 92 hastanın 41'i $(\% 44,5)$ kız ve 51'i $(\% 55,5)$ erkekti. Yaşları 3- 15 yaş arasında değişmekteydi (ortalama 10,1 yaş). Hastaların fizik muayene ve laboratuvar tetkikleri sonucunda; 32'sinde (\%35) ortopedik bozukluk, 31 'inde $(\% 33,6)$ üst solunum yolu enfeksiyonuna (ÜSYE) bağlı reaktif artrit, 21 'inde $(\% 22,8)$ travma ve $8(\% 8,6)$ olguda diğer sebepler saptandı. Tekrarlayan ağrıları olan $10(\% 10,8)$ hasta, büyüme ağrısı açısından takibe alınmış. Sonuç. Çocuklarda eklem şikâyeti sık karşılaşılan bir durum olup, büyüme ağrıları gibi inflamatuar olmayan nedenler kas-eklem ağrısının en sık sebebidir. Ancak romatizmal hastalıklar, enfeksiyonlar ve maligniteler gibi organik bütün nedenler mutlaka dışlandıktan sonra büyüme ağrısı tanısının konulması gerekir.

Anahtar sözcükler: Eklem ağrısı, çocuk, büyüme ağrısı, ekstremite ağrısı

\begin{abstract}
Aim. We aimed to determine the etiologies causing lower extremity pain in children and to identify the place of growth pain in the etiology. Method. The demographic and clinical characteristics, information about their diagnoses and the test results of the pediatric patients between 3-15 years of ages, admitted to pediatric, orthopedics and traumatology, and family medicine polyclinics with complaining of lower extremity pain from November to April 2011 were screened retrospectively from outpatient records. Results. Of 92 pediatric patients with lower extremity pain, $41(44.5 \%)$ patients were female and $51(55.5 \%)$ were male. Their ages ranged from 3 to 15 years (mean 10.1 years). As a result of physical examination and laboratory investigations of the patients, orthopedic disorders were diagnosed in $32(35 \%)$ patients, reactive arthritis due to upper respiratory tract infections (URTI) in 31 (33.6\%), trauma in $21(22.8 \%)$ and other causes in $8(8.6 \%)$ patients. $10(10.8 \%)$ patients with recurrent pain were followed up for growth pain. Conclusion. Joint complaint is a common condition in children and noninflammatory causes, such as growth pain, is the most common cause of muscle-joint pain. However, a diagnosis of growth pain should be established after the exclusion of all organic causes, such as rheumatic disorders, infections and malignancies.
\end{abstract}

Keywords: Arthralgia, growth pain, extremity pain

Geliş tarihi/Received: 10 Mart 2012; Kabul tarihi/Accepted: 11 Eylül 2012

\section{*İletişim adresi:}

Dr. Öznur Küçük, Çocuk Sağlı̆̆ı ve Hastalıkları Anabilim Dalı, Yeditepe Üniversitesi Tıp Fakültesi, TR-34755 İstanbul. E-posta: kilicoznur78@gmail.com 


\section{Giriş}

Çocuklarda kas- iskelet sistemi şikayetleri oldukça sıktır. Görülme oranı \%4-30 arasında değişmektedir [1,2]. Ağrı yakınması eklemlerde veya eklemler dışında (yaygın ağrı) diye ikiye ayrılabilir. Kas-iskelet sistemi ağrısının ayırıcı tanısı geniştir; Ancak olguların çoğunda nedenin kaynağı inflamatuardan çok mekaniktir ve uzun dönemde ağır sekele neden olmayabilir. Ancak travma ve malignensi gibi ağır ve yaşamı tehdit eden hastalıklarda da kas-iskelet sistemi şikayetleri görülebildiği unutulmamalıdır [3]. Ağrı ile başvuran çocukta öykü tanıya yaklaşımda önemlidir. Öykü alınırken ağrının yerleşimi, ağrının oluşum zamanı, süresi, niteliği, ağrının egzersiz ile ilişkisi, ağrıya eşlik eden sistemik bulgular, aşıla durumu, beslenme alışkanlıkları, psikolojik durumu ve travma dikkat edilmesi gereken noktalardır [4]. Kas-iskelet sistemi ağrısı ile başvuran çocukta yapılacak olan tam bir fizik muayene hekime önemli veriler sağlar. Ağrı yakınması olan çocuğa yapılacak fizik muayenede ateş, döküntü, eklem bulguları, subkutan nodüller, hepatosplenomegali, lenfadenomegali, kas gücü değerlendirilmesi ve yapısal iskelet anomalileri dikkat edilmesi gereken noktalardır $[5,6]$. Çocuğun büyüme ve gelişme durumu mutlaka değerlendirilmelidir. Eğer çocuk büyüme-gelişme geriliğine sahip ise öncelikle süreğen hastalıklar ayırıcı tanıda düşünülmelidir. Çocukluk yaş grubunda ağrı şikâyeti ile hekime başvuru nedeni olarak en sık büyüme ağrıları görülmektedir. $\mathrm{Bu}$ ağrıların büyüme ile ilişkisi gösterilememiş olup, başvuru nedeni olduğundan dolayı bu isimlendirme yaygın olarak kullanılmaktadır. Fizik muayenede ağrılı dönemde bile bir özellik saptanmaz. Ancak bu tanıyı koymadan önce başka bir hastalığa ait belirtiler dikkatlice aranmalıdır [7]. Çalışmada çocuklardaki alt ekstremite ağrılarının nedenlerini gözden geçirip, büyüme ağrılarının etiyolojideki yerinin belirlenmesi amaçlandı.

\section{Gereç ve yöntem}

Kasım-Nisan 2011 tarihleri arasında Ortopedi, Çocuk ve Aile Hekimliği polikliniğine alt ekstremite ağrısı ile başvuran 3-15 yaş grubundaki çocukların demografik ve klinik özellikleri, tetkik sonuçları ve tanılarına ait bilgiler poliklinik dosya kayıtlarından geriye dönük olarak elde edildi. Hastalar kas- iskelet sistemi hastalığı ayırıcı tanısına yönelik olarak öykü, fizik muayene ve laboratuvar tetkikleri yönünden incelendi. Tüm değerlendirmeler sonucunda Peterson kriterlerine göre büyüme ağrısı tanısı konuldu.

\section{Bulgular}

Eklem ve bacak ağrısı ile başvuran 92 hastanın 41'i $(\% 44,5)$ kız ve 51'i $(\% 55,5)$ erkekti. Yaşları 3-15 yaş arasında değişmekteydi (ortalama 10,1 yaş). Hastalar fizik muayene ve laboratuvar olarak incelendiğinde; 32'si (\%35) ortopedik bozukluk, 31'i $(\% 33,6)$ üst solunum yolu enfeksiyonuna (ÜSYE) bağlı reaktif artrit, 21'inde $(\% 22,8)$ travma ve 8 $(\% 8,6)$ olguda diğer sebepler saptandı (Şekil 1). Hastalarımızın hepsi (\%100) ekstremite ağrısı ile başvurmuşlar. Aktif artrit bulgusu saptanmadı. 36'sı $(\% 39,1)$ ayak ağrısı, 7'si $(\% 7,7)$ kalça ağrısı ve 49'u $(\% 39,1)$ diz ağrısı mevcuttu.

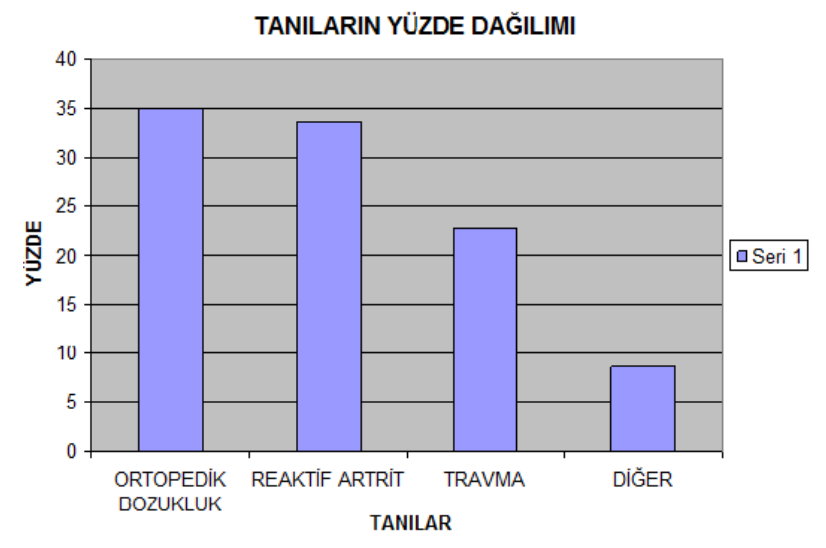

Şekil 1. Olguların tanı dağılım yüzdeleri. 
Ortopedik sorunların dağılım yüzdeleri ve diğer sebeplerin dağılım yüzdeleri şekil 2 ve şekil 3'de gösterilmiştir.

ORTOPEDIK SORUNLARIN DAĞILIM YÜZDESI

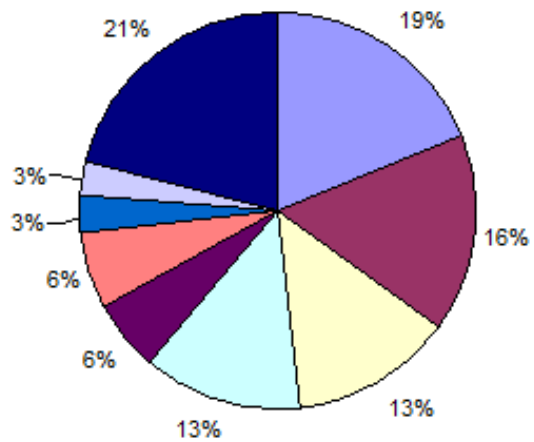

\begin{tabular}{l}
\hline AVASKÜLER NEKROZ \\
$\square$ TIRNAK BATMASI \\
$\square$ MIYALJI \\
$\square$ TÜMORAL \\
DÜZ TABAN \\
$\square$ SKOLYOZ \\
$\square$ SPINA BFIDA \\
$\square$ SINOVIT \\
$\square$ DIĞER
\end{tabular}

Şekil 2. Ortopedik sorunların dağılım yüzdesi.

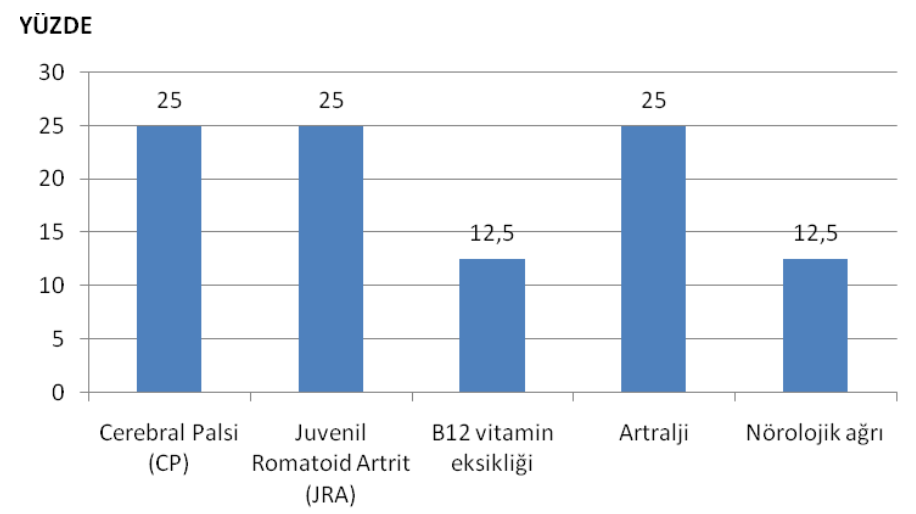

Şekil 3. Diğer sebeplerin dağılım yüzdeleri.

ÜSYE'na bağlı reaktif artrit olgularının 12'sinde (\%38,7) Anti Streptolizin O yüksek ve 19 'da $(\% 61,3)$ normal saptanmıs ve hastaların hepsinde ÜSYE tedavisi sonrası kontrolde şikâyetleri gerilemişti.

Daha önce ÜSYE bağlı reaktif artrit tanısı alan 8 hasta, nörolojik ağrı tanısı alan 1 hasta ve artralji tanısı alan 1 hasta, toplam 10 hastada $(\% 10,8)$ tekrarlayan ağrilar saptandı. Tekrarlayan ağrılar 7 hastada (\%70) ayak ağrısı ve 3 hastada (\%30) diz ağrısı șeklinde ifade ediyorlardı. $\mathrm{Bu}$ hastalar diğer sebepler dışlandıktan sonra büyüme ağrısı açısından takibe alındi.

\section{Tartışma}

Eklem şikâyeti olan bir çocukta, olayın inflamatuar bir eklem tutulumu olup olmadığının anlaşılması, tanıya yaklaşım açısından en önemli ölçüttür. İnflamatuar olmayan kaseklem ağrısı çocukluk döneminde en sık rastlanan şikâyetlerdendir. Ancak diğer nedenlerin mutlaka dışlanması gereklidir [8]. Yüksek ateş, kırıklık, kilo kaybı, eklem hareketlerinde azalma, eklemde ödem, simetrik olmayan bacak ağrıları ya da sabahları eklem sertliği gibi başka bir bulgu varlığında daha fazla laboratuvar ve X-1şını testleri ile diğer nedenler dışlandıktan sonra Peterson kriterleri (atipik büyüme ağrıları) ile büyüme ağrısı tanısı konulabilir.

Kronik romatizmal hastalıklar sakatlıklara neden olabildiği için erken tanı sekellerin önlenmesi bakımından önemlidir. Olguların çoğunda dikkatli bir klinik muayene, çocuk ve adolesanlarda kas- iskelet sisteminin bilinmesi ve birkaç uygun inceleme doğru tanıya götürebilmektedir. Hastalarımızın 5'in $(\% 5,4)$ 'de kronik hastalık tespit edilmiş olup takibe alınmıştır (Serebral palsi (2), Juvenil Romatoid artrit (2), Spina bifida(1)). 
İlk olarak 1823 ’te Duchamp tarafından büyüme ağrıları terimi ortaya atılmıştır $[9,10]$. Çok sayıda adolesanda artmış kas-iskelet ağrısı hızlı kemik gelişimine bağlanmıştır. Epidemiyolojik çalışmalarda bu bağlantı kanıtlanamamıştır [1]. Bennie ve ark. [11] gün içinde artmış egzersizin rol oynadığını göstermiş, Seham ve Hilbert [12] buna ek olarak yetersiz uykunun da bir faktör olabileceğini düşünmüşlerdir. Hawksley [13], büyüme ağrısı saptanan 115 çocuğu incelemiştir. $\mathrm{Bu}$ çalışmada romatoid ateş ile bağlantı kurulamamış, platipodia, skolyoz ve valgus knee gibi orta derece ortopedik sorunlar tespit edilmiştir. Bu bulgular "büyüme ağrıları" tanımlamasının tam olarak doğru bir gerçekliği ifade etmeyebileceğini göstermektedir.

Tekrarlayan alt ekstremite ağrıları (büyüme ağrıları=growth pains) çocuklardaki kasiskelet sistemi ağrılarının inflamatuar olmayan en sık sebebidir [14]. Büyüme ağrıları, 312 yaş arası çocuklarda genellikle bacaklarda (dizin arkası, uyluk ve baldırlarda), daha az sıklıkla bacaklara ek olarak kollarda da görülebilen, akşam ve gece vakti ortaya çıkan, uykudan uyandıran, birkaç dakikadan birkaç saate kadar sürebilen ve nedeni bilinmeyen ağrılar olarak tanımlanmaktadır. Hastalarımızın hepsinde ağrılı eklem ve ekstremite ağrısı ile başvurdular. 36'sı (\%39,1) ayak ağrısı, 7'si $(\% 7,7)$ kalça ağrısı ve 49'u $(\% 39,1)$ diz ağrısı mevcuttu. Çoğunlukla büyümenin en açı kanıtı olan kollar ve bacakları etkilediğinden büyüme ağrıları adı verilmiştir. Genelde, yoğun fiziksel aktivite sonrası görülmektedir. Birçok araştırmacı tanı ölçütleri geliştirmeye çalışmalarına rağmen en faydalı olan klinik bulgulara dayanan Peterson kriterleridir [15]. Daha sonra Russel ve Abu- Arafeh [16]. tarafindan tamamlanmıştır. Büyüme ağrılarındaki ölçütler çocukların şimdiki klinik tablosu ve alt ekstremitede tekrarlayan ağrılara dayanır. Bu ağrılar 72 saatten az sürer, kemik de lokalize olamaz ve birden fazla eklemde hareket kısıtlılığına sebep olmaz. Travma, ödem, kızarıklık, lokalize olabilen hassasiyet veya başka genel ve bölgesel inflamasyon bulguları yoktur. Büyüme ağrılarının sıklığı değişkendir (\%2,6$\% 49,4)$ [17]. Son çalışmalarda 4-6 yaş arasındaki çocuklarda prevalans \%38,3 olarak tespit edilmiştir $[10,18]$.

Çalışmamızda büyüme ağrısı tanısı konulmadan önce diğer sebeplerin de gözden geçirilmesi gerektiğini vurgulamak istedik. Çocuklarda eklem şikâyeti sık karşılaşılan bir durum olup, inflamatuar olmayan nedenler kas- eklem ağrısının en sık sebebidir. Ancak romatizma, enfeksiyon, malignite gibi organik bütün nedenler mutlaka ekarte edildikten sonra büyüme ağrısı tanısının konulması gerekir.

\section{Kaynaklar}

1. Goodman JE, McGrath PJ. The epidemiology of pain in children and adolescents: a review. Pain 1991: 46: 247-64.

2. Symmons DP, Jones M, Osborne J, Sills J, Southwood TR, Woo P. Pediatric rheumatology in the United Kingdom: data from the British Pediatric Rheumatology Group National Diagnostic Register. J Rheum 1996; 23: 1975-80.

3. Foster H, Khawaja K. When to request a paediatric rheumatology opinion. Current Paediatrics 2005; 15: 1-8.

4. Kasapçopur Ö. Çocukluk çağı romatizmal hastalıklarına tanılandırıcı yaklaşım. İ.Ü. Cerrahpaşa Tıp Fakültesi Sürekli Tıp Etkinlikleri, Sempozyum dizisi 2003; 34: 43 50 .

5. Kasapçopur Ö, Arısoy N. Çocukluk Çağı Romatizmal Hastalıklarında Ayırıcı Tanı. Turkiye Klinikleri J Pediatr Sci 2008, 4: 7-11.

6. Bostan Ö. Çocuklarda Eklem Şikâyetlerine Yaklaşım. Güncel Pediatri 2004; 2: 12633.

7. Peterson H. Growing pains. Pediatr Clin North Am 1986; 33: 1365.

8. Cassidy J.T, Petty R.E. Musculoskeletal Pain Syndromes Of Nonrheumatic Origin. In: Pediatric Rheumatology. 3rd edition. Pennsylvania: Saunders Company, 1995; pp: 108-32.

9. Duchamp M. Maladies de la croissance. In: Levrault FG, editor. Mémoires de médecine practique. Paris: Jean-Frédéric Lobstein; 1823. 
10. Evans AM, Scutter SD, Lang LG, BR. Dansie. "Growing pains" in young children: A study of the profile, experiences and quality of life issues of four- to six-year-old children with recurrent leg pain. Foot 2006; 16: 120-4.

11. Bennie PB. Growing pains. Arch Pediatr 1894; 11: 337-47.

12. Seham M, Hilbert EH. Muscular rheumatism in childhood. Am J Dis Child 1933; 46: 826-33.

13. Hawksley JC. The nature of growing pains and their relation to rheumatism in children and adolescents. BMJ 1939; 1: 155-7.

14. Al Khattat A, Campell J. Recurrent limb pain in childhood ("Growing pains"). Foot 2000; 10: 117-23.

15. Petersen HA. Leg aches. Pediatr Clin North Am 1977; 24: 731-6.

16. Abu-Arafeh I, Russell G. Recurrent limb pain in schoolchildren. Arch Dis Child 1996; 74: 336-9.

17. Williams MF. Rheumatic conditions in school children. Lancet 1928; 211: 720-1.

18. Evans AM, Scutter SD. Prevalence of "Growing Pains" in young children. J Pediatr 2004; $145: 255-8$. 